\title{
Gurcharan Das, The Difficulty of Being Good. On the Subtle art of Dharma
}

Oxford University Press, New York, 2010, LII + 434 p.

André Padoux

\section{(2) OpenEdition}

\section{Journals}

\section{Édition électronique}

URL : http://journals.openedition.org/assr/23471

DOI : $10.4000 /$ assr.23471

ISSN : $1777-5825$

Éditeur

Éditions de l'EHESS

Édition imprimée

Date de publication : 31 décembre 2011

Pagination : 150

ISBN : 9782713223273

ISSN : 0335-5985

Référence électronique

André Padoux, « Gurcharan Das, The Difficulty of Being Good. On the Subtle art of Dharma », Archives de sciences sociales des religions [En ligne], 156 | octobre-décembre 2011, document 156-38, mis en ligne le 14 février 2012, consulté le 21 septembre 2020. URL : http://journals.openedition.org/assr/ 23471 ; DOI : https://doi.org/10.4000/assr.23471

Ce document a été généré automatiquement le 21 septembre 2020.

(c) Archives de sciences sociales des religions 


\title{
Gurcharan Das, The Difficulty of Being Good. On the Subtle art of Dharma
}

Oxford University Press, New York, 2010, LII + 434 p.

\author{
André Padoux
}

\section{RÉFÉRENCE}

Gurcharan DAS, The Difficulty of Being Good. On the Subtle art of Dharma, Oxford University Press, New York, 2010, LII + 434 p.

1 Cet ouvrage, dont on peut penser qu'il ne relève pas exactement des sciences sociales des religions, mérite cependant d'être signalé ici. D'abord parce qu'il repose sur le Mahâbhârata, la plus longue épopée indienne - une des plus longues du monde -, et sans doute la seule à être encore vivante. Quoique en sanskrit, elle est toujours lue ou récitée (parfois jouée, l'Occident ayant d'ailleurs eu sur ce point un certain rôle). Elle continue dès lors, parfois sous des formes populaires, de former un fonds toujours présent à l'esprit des Indiens hindous auquel il leur arrive de se référer quand se posent à eux des problèmes moraux - ce dernier point étant le thème de ce livre et en faisant l'intérêt. Ensuite, parce que - trait typiquement indien - il a été rédigé par un dirigeant de la branche indienne d'une importante multinationale, lequel, la cinquantaine venue, a, comme il l'explique, pris sa retraite en renonçant au monde des affaires; il a alors appris le sanskrit et s'est plongé dans l'étude du Mahâbhârata, ce qui lui a donné l'idée de voir s'il en pouvait tirer des enseignements moraux applicables dans le monde d'aujourd'hui.

2 Le trait particulier de cette épopée fondatrice indienne est que ce récit d'une guerre, qui oppose les enfants de deux frères, se termine par une victoire qui, si elle amène la destruction d'un des camps, n'est pour les vainqueurs que sujet de tristesse: «la victoire me semble plutôt une défaite " conclut le vainqueur. La guerre a commencé 
pour une raison futile (une perte de jeu). Alors que le combat se déroule dans le " champ du dharma ", de la loi morale, et que les vainqueurs incarnent en principe le camp du droit, de la justice, ceux-ci n'ont triomphé qu'en utilisant parfois des moyens déloyaux, et le royaume reconquis par les Pandavas sur leur cousins Kauravas est dévasté. Ils y règneront sans joie. Même le dieu Krishna qui les a menés à la victoire (plusieurs fois par la ruse, d'ailleurs) est, à la fin, tué dans un accident de chasse. Le dharma, la loi qui doit gouverner les hommes pour leur bien et celui du monde, ne peutil donc parfois triompher que par le moyen du mal ? Rien n'est simple. La richesse (et donc l'intérêt, l'actualité) du Mahâbhârata tient notamment au refus de donner des réponses claires, de répartir clairement les torts et les mérites. Ses héros sont constamment confrontés à des options contradictoires sur le plan moral. Les Pandavas, dont le chef a causé la guerre par son amour du jeu, n'apparaissent pas toujours sous un jour flatteur, cependant que leurs ennemis, les Kauravas, le camp des "méchants ", sont souvent décrits comme courageux, généreux, loyaux. Les guerriers de l'Odyssée se posaient moins de problèmes.

3 Après avoir résumé l'épopée et en avoir présenté les personnages, l'auteur envisage, dans neuf chapitres, le cas de neuf des héros du Mahâbhârata, avec les problèmes qui se sont posés à eux : de la jalousie, avec Duryodhana, au remords de Yudhishthira, en passant par le courage de Draupadi, femme admirable, le désespoir (Arjuna), le désintéressement (Bhishma), etc. Dans le dernier chapitre, il revient sur le problème du dharma, pour finir par le dharma et sur ce que peut être aujourd'hui le message du Mahâbhârata.

4 Les cas exposés dans neuf chapitres sont autant d'occasions pour aborder non seulement des problèmes généralement humains mais aussi ceux de l'Inde contemporaine, dont il est devenu un spécialiste reconnu : ses articles dans la presse indienne font autorité et dans un ouvrage récent, India Unbound, il a donné un tableau très pénétrant, et sévère, de la situation intérieure actuelle de son pays. Ainsi rappelle$\mathrm{t}$-il, à propos de Duryodhana, un scandale récent touchant les frères Ambani ( $6^{\mathrm{e}}$ fortune mondiale) dont la brouille avait failli faire sombrer leur entreprise et donc faire perdre leur travail à des milliers d'employés. La firme a finalement été sauvée, mais elle n'avait $\mathrm{pu}$ naître et croître, puis devenir une des premières de l'Inde qu'en profitant sans scrupule de la corruption des autorités publiques indiennes. On sait que la corruption (apparue, et croissant sans cesse, depuis l'indépendance) ronge l'Inde, pays où des parlementaires sont accusés de crimes divers (escroquerie, vol, assassinat) sans que cela influe le moins du monde sur leur carrière politique, toute bâtie sur la violence ou la corruption. L'Inde a pour devise "seule la vérité triomphe", accolée à un chapiteau d'une inscription de l'empereur Ashoka lequel, devenu bouddhiste, avait, il y a plus de deux mille ans, regretté publiquement les malheurs infligés à son peuple par ses guerres : son exemple n'a guère été suivi. Mais la préoccupation morale, toujours liée à la religion, a constamment eu sa place en Inde (voir le rôle du mahatma Gandhi), même s'il s'en faut de beaucoup qu'elle soit restée présente chez ceux qui s'y activent ou la gouvernent. On a rendu compte ici il y a peu (Arch. 152-73) d'un ouvrage sur les liens souvent étroits existant, en Inde, entre richesse et religion. On y montrait par exemple des chefs d'entreprise qui prenaient leur rôle de direction comme une sorte de yoga des œuvres, karmayoga, selon l'enseignement de la Bhagavad Gîtâ. Y étaient aussi présentées des castes marchandes qui jugent qu'en s'enrichissant ses membres accomplissent leur svadharma, la loi religieuse qui est la leur, gagnant par là du mérite religieux (ou même contribuant au maintien de l'ordre sociocosmique, etc.). L'Inde ou 
les ambiguïtés! C'est que la notion de dharma (qui reste présente dans la vie des hindous, puisque c'est l'ensemble des principes gouvernant le monde hindou) n'est pas simple : le dharma est englobant dans ses préceptes ; reposant sur une base védique, il a été élaboré au cours des siècles et garde de ce passé des préceptes parfois contradictoires. «Being good » en suivant l'enseignement est certainement difficile. Et l'auteur, en se référant au Mahâbhârata, a de la peine à en tirer des règles de conduites précises.

5 Son livre n'en mérite pas moins lecture, car il montre, avec la présence durable d'un grand texte mythique, la réaction d'un Indien d'aujourd'hui à l'ordre traditionnel de la civilisation de l'Inde. Gurcharan Das, né dans cette tradition, mais dans un milieu moderne cultivé, donc largement marqué dans sa formation par l'influence britannique - dont on ne saurait sous-estimer la marque durable sur l'Inde - porte, de ce fait, sur le Mahâbhârata un regard en quelque mesure extérieur tout en restant profondément indien. Son étude a en outre le mérite de nous rappeler l'existence d'un grand texte («texte» pour nous qui ne pouvons que le lire - mais nous l'avons aussi vu grâce à Peter Brooks), dont il n'y a malheureusement à ce jour pas de traduction française valable et accessible : nous n'en connaissons guère que la Bhagavad Gîtâ (une très bonne nouvelle traduction et présentation par Michel Hulin en a paru en 2010) : ce livre-ci est donc une bonne opportunité pour découvrir (ou retrouver), sinon l'enseignement pratique de l'épopée, du moins sa richesse et son intérêt. 